\title{
Switched PI Control Based MRAS for Sensorless Control of PMSM Drives Using Fuzzy-Logic- Controller
}

Zhao-hua Liu ( $\sim$ zhaohualiu2009@hotmail.com )

Hunan University of Science and Technology https://orcid.org/0000-0002-6597-4741

Jie Nie

Hunan University of Science and Technology

Hua-Liang Wei

The University of Sheffield NATCECT: The University of Sheffield

Fa-Ming Wu

Lanzhou University of Technology

Lei Chen

Hunan University of Science and Technology

Zhu Zhang

Hunan University of Science and Technology

\section{Original Article}

Keywords: Fuzzy logic control (FLC), model reference adaptive system (MRAS), proportion integration (PI), nonlinearity, PMSM, sensorless control

Posted Date: August 30th, 2021

DOI: https://doi.org/10.21203/rs.3.rs-847318/v1

License: (c) (i) This work is licensed under a Creative Commons Attribution 4.0 International License. Read Full License 


\title{
Switched PI Control Based MRAS for Sensorless Control of PMSM Drives Using Fuzzy-Logic-Controller
}

\author{
Zhao-Hua Liu ${ }^{1}$ Jie Nie $^{1} \cdot$ Hua-Liang Wei ${ }^{2} \cdot$ Fa-Ming Wu ${ }^{3} \cdot$ Lei Chen $^{1} \cdot$ Zhu Zhang $^{1}$
}

\begin{abstract}
With the use of sensorless control mechanical position sensors can be removed from the gearbox, so as to decrease the maintenance costs and enhance the system robustness. In this paper, switched PI control based model reference adaptive system (MRAS) observer using Fuzzy-Logic-Controller (FLC) is introduced for sensorless control of permanent magnet synchronous motor (PMSM) drives. The main work and innovation of this paper include: 1) An FLC is designed for speed and current control. The response performance of speed regulation and the accuracy of the command voltage are improved and the difficulty of manual adjustment of control parameters is avoided. In addition, the disturbance observer is established to compensate the nonlinear effect caused by voltage source inverter (VSI). Therefore, the robustness of PMSM vector control system is improved and the sensorless control precision is guaranteed. 2) A sensorless control strategy of a switched PI control based MRAS observer is proposed for stator resistance tracking, which can improve the accuracy of resistance estimation and improve the dynamic performance of sensorless control. 3) The experimental results are given to verify the availability of the proposed scheme.
\end{abstract}

Keywords: Fuzzy logic control (FLC), model reference adaptive system (MRAS), proportion integration (PI), nonlinearity, PMSM, sensorless control.

\section{Introduction}

PERMANENT-MAGNET synchronous motors (PMSM) have been broadly applied in electric vehicles, flywheel energy storage systems, and wind energy conversion systems [1]-[3]. Field-oriented control (FOC) is a common speed control technique for PMSM [4]. However, the use of encoders, resolvers, Hall effect sensors or other mechanical position sensors increase the maintenance costs and decrease the system robustness [5]-[8]. Therefore, the

Zhao-Hua Liu

zhaohualiu2009@hotmail.com

1 the School of Information and Electrical Engineering, Hunan University of Science and Technology, Xiangtan 411201, China

2 the Department of Automatic Control and Systems Engineering, University of Sheffield, Sheffield S1 3JD, U.K.

3 CRRC Zhuzhou Institute Company Ltd, Zhuzhou, 412007, China sensorless control methods have attracted extensive attention.

In many sensorless systems using back EMF, the steady-state module of PMSM is often utilized as a reference; consequently, robustness may be difficult to achieve if there is a parameter mismatch or load sudden change during the working operation under the low speed range [9], [10]. Due to the stator resistance of PMSM varies with temperature, robustness and precise multi-parameter identification is necessary for low speed sensorless driver [11], [12]. Therefore, some multi-parameter identification technologies such as extended Kalman filter (EKF) scheme [13], [14], recursive least squares (RLS) scheme [15], [16], and model reference adaptive system (MRAS) scheme [22]-[25] have been proposed. In [14], the EKF scheme gave appropriate experimental result in parameter identification. Nevertheless, the control algorithm has some limitations such as complex algorithmic structure, requirement of proper initialization. The RLS scheme for estimating electrical parameters proposed in [15] and [16] has a fast convergence speed. Unfortunately, due to the algorithm involves a large number of differential equations, the performance of microprocessor decreases and the system response is slow.

Among the methods mentioned above, MRAS scheme has the advantages of simplicity, good stability and small amount of calculation, which has been testified to be one of the best methods introduced in the literature. Usually, a single PI controller is adopted in the MRAS scheme to calculated the position or rotor speed of PMSM due to its simple structure. However, voltage-source inverter (VSI) nonlinearity and the change of PMSM parameter become more important at low speed operation. All this can make the single PI controller unable to maintain the robustness of the control system. Therefore, a variety of solutions with more advanced algorithms are proposed, which provide alternatives to the adaptation mechanism for MRAS scheme. In [18], a fuzzy logic controller (FLC) was employed in MRAS for speed regulation so that system are more robust than a PI controller to parameter uncertainties and sensor noises. A two-dimensional FLC based MRAS method was introduced in [19]. However, the method may 
be more complicated and computationally expensive when it is adopted in the MRAS scheme to displace the conventional PI adaptation mechanism. In [20], an artificial neural network (ANN) method had been utilized in MRAS scheme for stator resistance estimation and good experimental results have been obtained. In this paper, the switched PI control is designed based on the MRAS observer for realizing stator resistance tracking, which can improve the robustness of sensorless control for PMSM.

In addition, the accuracy of PMSM sensorless method depends on the command voltages. Traditionally, the proportional-integral (PI) controller is usually utilized in many industrial applications because of their simple implementation. The fixed-gain PI controller is mainly affected by the parameter variation and external disturbance such as step changes of reference speed and load sudden change. Accordingly, PI controller cannot guarantee a reasonable dynamic and steady-state performance during the whole working operation range. For overcoming the disadvantage, some improved controllers are proposed [21]-[27]. In [21], Yasser et al. employed d-axis sliding-mode control method to displace the conventional d-axis PI current controller in torque-control technology and achieved good performance. In the FLC scheme, the control parameters can be adjusted properly by fuzzy rules, which can be used to build a logical model of the mankind behavior[22]. In conclusion, the FLC has clear edges over the conventional PI controller: 1) it is more simple and has less intensive mathematical design requirements; 2) it is more stable than the traditional PI controller; 3) it has the ability to deal with nonlinear function with arbitrary complicacy [23]. The expert system and fuzzy logic have been employed for servo system to enhance control performance [24], [25]. In [26], a self-tuning PI control method using ANN was introduced to train the regulator to meet the design requirements under various working conditions. Besides, a recurrent fuzzy neural cerebellar model articulation network was also introduced in [27]. Although these intelligent methods seem to be powerful in some specific situations, the large amount of training is inevitable .

Moreover, a VSI is employed to supply power to the PMSM, and the voltages required by MRAS observer are obtained from the PI controller in the FOC drive of the PMSM. The voltage used for MRAS observer is often derived from the output signal of current loop, while the terminal voltage of PMSM is obtained from VSI, which is hard to measure [28]. It should be noted there is usually an error caused by the VSI nonlinearity between the output signals of the current loop and the output voltages of VSI.
Therefore, the VSI nonlinearity should be compensated properly for improving the control performance of PMSM [29]. Generally, the VSI turbulence voltage is estimated by utilizing the related parameters of switching devices, and then the reference is compensated [30]. In this paper, the VSI nonlinearity caused by VSI is calculated by the disturbance observer, which is compensated properly.

In this manuscript, a FLC is introduced for speed and current controller. The parameters(i.e., $\mathrm{Kp}$ and $\mathrm{Ki}$ ) can be adjusted by utilizing fuzzy control rules. The presented scheme can enhance the control performance of rotor speed and the precision of command voltage. Furthermore, the VSI nonlinearity caused by VSI is calculated by the disturbance observer, which is fed back to the $d / q$ current controller. In the end, the switched PI control is designed based on the MRAS observer for realizing stator resistance tracking, which can enhance the robustness and accuracy of sensorless control. The main work of this manuscript is concluded as follows:

1) A FLC is designed for speed and current regulator control to ensure robust response. Since the speed error (E) and error change speed (EC) of current regulator are smaller than that of speed controller, five membership functions (MF) are applied to reduce the amount of calculation. In addition, the membership functions are designed to be more dense at the origin for improving the steady-state control performance. Furthermore, an improved fuzzy rule is proposed in current controller to make the output adjustment of FLC more appropriate.

2) To ensure an accurate reference tracking, a switched PI system is proposed to replace the traditional PI adaptive mechanism for resistance tracking in the MRAS observer. The principle of this approach is simple and easy to implement. Under this scheme, the MRAS observer can choose proper PI controller and further determine whether the integral coefficients $\mathrm{Ki}$ (see Figure 11) is needed to avoid overshoot and achieve robust response against different uncertainties such as parameter variation.

We organize this paper in the following parts. In Section II, the relevant functions of PMSM are analyzed and presented by considering the VSI nonlinearities. In Section III, a FLC scheme for speed and current regulators is proposed. In Section IV, an MRAS with a switched PI scheme is proposed. The relevant Simulink results are exhibited in Section $\mathrm{V}$ to show the robustness and stability of the proposed method. Finally, brief conclusions are given in Section VI. 

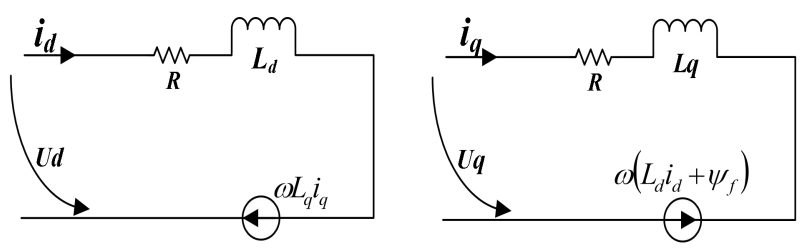

Figure 1 The equivalent electric circuits of PMSM.

\section{Modeling of PMSM Considering VSI Nonlinearity}

In the $d$ and $q$ axis two-phase rotating coordinate system, the equivalent electric circuits of PMSM are given in Figure 1. The stator voltages for PMSM under $\mathrm{d} / \mathrm{q}$ axis can be depicted as:

$$
\begin{gathered}
\left\{\begin{array}{l}
u_{d}=R_{s} i_{d}+L_{d} p i_{d}-\omega_{e} L_{q} i_{q} \\
u_{q}=R_{s} i_{q}+L_{q} p i_{q}+\omega_{e} L_{d} i_{d}+\omega_{e} \varphi_{f}
\end{array}\right. \\
\left\{\begin{array}{l}
\varphi_{q}=L_{q} i_{q} \\
\varphi_{d}=L_{d} i_{d}+\varphi_{f}
\end{array}\right.
\end{gathered}
$$

where $p$ stands for $(d / d t)$ operator, the subscript $d$ and $q$ represents the $d / q$ axis, $u_{d}$ and $u_{q}$ are stator voltage components, $i_{d}$ and $i_{q}$ are stator current components, $L_{d}$ and $L_{q}$ are the stator inductances, $\varphi_{d}$ and $\varphi_{q}$ are rotor flux components, $R_{s}$ is the stator resistance, $\omega_{e}$ is the electrical angular velocity, $\varphi_{f}$ is the PM flux.

For the surface-mounted PMSM, the torque under the control strategy $i_{d}=0$ could be reported as:

$$
\begin{gathered}
T_{e}=1.5 P \varphi_{f} i_{q} \\
T_{e}-T_{L}=J \dot{\omega}+B \omega
\end{gathered}
$$

where $P$ is the number of pole pairs, $J$ and $B$ are inertia and viscous friction, respectively, and $T_{e}$ and $T_{L}$ are electrical and load torque.

Because the switch time of the industrial device is finite, it is necessary to consider dead time of pulse width modulation (PWM) gate signal for preventing two switch devices on the same arm of inverter from conducting at the same time.

Table 1 Relevant parameters of the VSI

\begin{tabular}{cc||cc}
\hline \hline DC bus voltage & $560[\mathrm{~V}]$ & Switch period & $86.9[\mu \mathrm{s}]$ \\
Dead-time & $4[\mu \mathrm{s}]$ & Switch device & IGBT \\
Turn-on time & $0.8-2.0[\mu \mathrm{s}]$ & Turn-off time & $2.0-2.9[\mu \mathrm{s}]$ \\
$\begin{array}{c}\text { Saturation } \\
\text { voltage }\end{array}$ & $1.8-2.7[\mathrm{~V}]$ & $\begin{array}{c}\text { Diode forward } \\
\text { voltage }\end{array}$ & $2.2-2.3[\mathrm{~V}]$ \\
\hline \hline
\end{tabular}

Table I gives the specifications of VSI. It is not hard to state the dead-time effect of A phase arm. Figure 2 exhibits the structure diagram of A phase arm of the PWM inverter, where the insulated gate bipolar transistors are employed as switch equipment. In the course of $T_{d}$, both the switch devices $Q_{1} / Q_{4}$ in the same arm are closed, so the flow direction of the phase current $i_{a}$ determines the output voltage. When the flow direction of the $i_{a}$ is positive, the $i_{a}$ flows through the bottom diode $D_{4}$ in the course of dead-time, and vice versa.

Figure 3 exhibits the flow direction of A phase current. According to Figure 3, considering the dead-time compensation voltage (DTCV), function (1) can be given as follows:

$$
\left\{\begin{array}{l}
u_{d}^{*}+u_{d . \text { oom }}=R_{s} i_{d}+L_{d} p i_{d}-\omega_{e} L_{q q} i_{q}+u_{d . d \text { dead }} \\
u_{q}^{*}+u_{q . \text {.om }}=R_{s} i_{q}+L_{q} p i_{q}+\omega_{e} L_{d} i_{d}+\omega_{e} \varphi_{f}+u_{q . \mathrm{ded} d}
\end{array}\right.
$$

where $u_{d . c o m}$ and $u_{q . c o m}$ are $d$ - and $q$-axis voltage compensation of VSI nonlinearity, respectively, $u_{d . d e a d}$ and $u_{q \text {.dead }}$ are $d$ - and $q$-axis disturbance voltage caused by VSI nonlinearity, respectively. In addition, the turbulence voltage in the rotating coordinate system under the control strategy $i_{d}=0$ can be represented as follows:

$$
\begin{gathered}
{\left[\begin{array}{c}
V_{q, \text { dead }} \\
V_{d, \text { dead }}
\end{array}\right]=V_{\text {dead }} \cdot \mathbf{K}^{r}\left(\theta_{r}\right)\left[\begin{array}{c}
\operatorname{sgn}\left(i_{\mathrm{qs}} \cos \theta_{r}\right) \\
\operatorname{sgn}\left(i_{\mathrm{qs}} \cos \left(\theta_{r}-\frac{2 \pi}{3}\right)\right) \\
\operatorname{sgn}\left(i_{\mathrm{qs}} \cos \left(\theta_{r}+\frac{2 \pi}{3}\right)\right)
\end{array}\right]} \\
V_{\text {dead }}=\frac{T_{\text {dead }}+T_{\mathrm{on}}-T_{\mathrm{off}}}{T_{s}} \cdot\left(V_{\mathrm{dc}}-V_{\mathrm{sat}}+V_{d}\right)+\frac{V_{\mathrm{sat}}+V_{d}}{2}
\end{gathered}
$$

where $V_{\text {dead }}$ is the disturbance voltage, $T_{o n}$ and $T_{\text {off }}$ are turn-on/off delay time, respectively, $T_{d}$ is dead time, $V_{\text {sat }}$ is

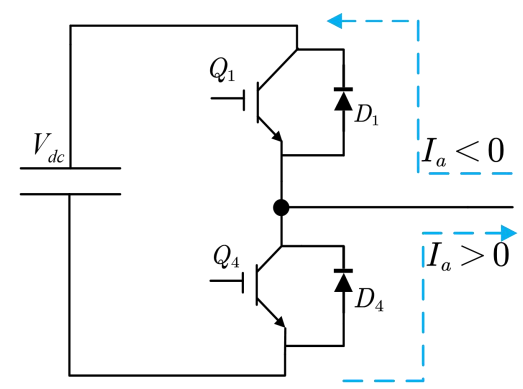

Figure 2 The block diagram of A phase arm of VSI.

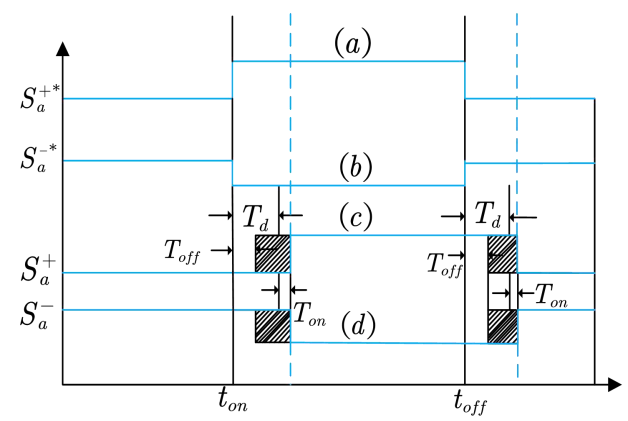

Figure 3 The gate trigger pulse of A-phase bridge arm. 


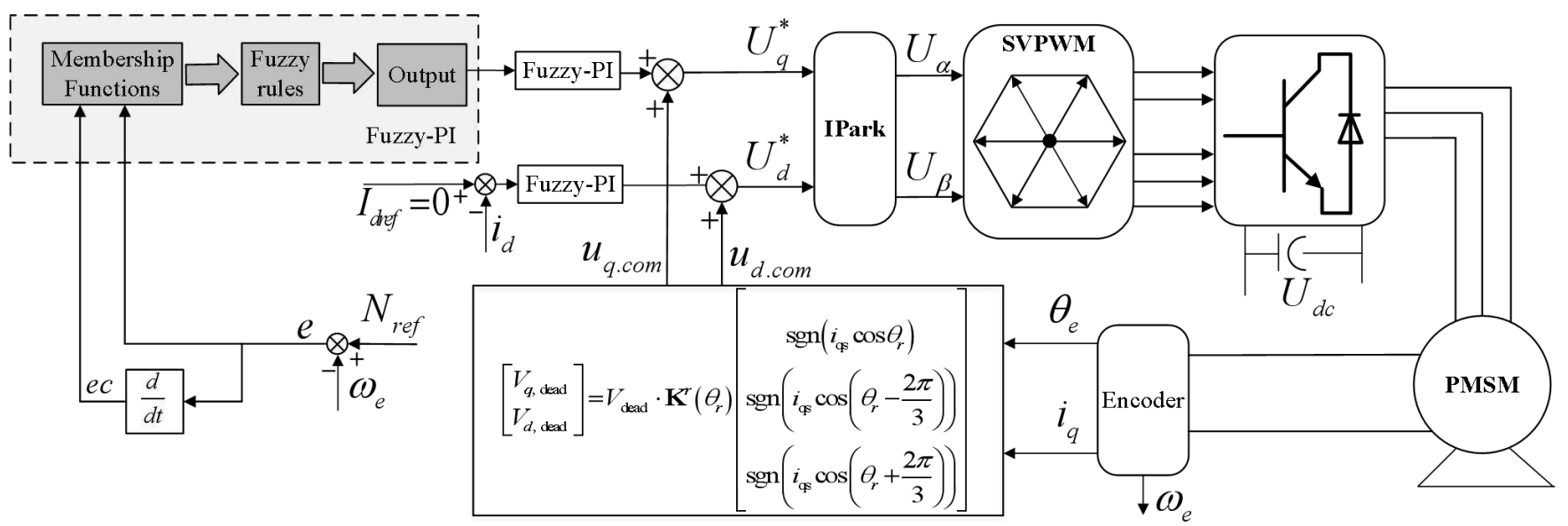

Figure 4 Overall sensorless control block diagram with the fuzzy logic controller considering VSI nonlinearity compensation.

saturation voltage drop of the active switch, $V_{D}$ is diode forward voltage. $\mathbf{K}^{r}\left(\theta_{r}\right)$ is the rotation factor and can be depicted as:

$$
\mathbf{K}^{r}\left(\theta_{r}\right)=\frac{2}{3}\left[\begin{array}{lll}
\cos \left(\theta_{r}\right) & \cos \left(\theta_{r}-\frac{2 \pi}{3}\right) & \cos \left(\theta_{r}+\frac{2 \pi}{3}\right) \\
\sin \left(\theta_{r}\right) & \sin \left(\theta_{r}-\frac{2 \pi}{3}\right) & \sin \left(\theta_{r}+\frac{2 \pi}{3}\right)
\end{array}\right]
$$

\section{The Proposed Fuzzy Logic Controller for Speed and Current Loop}

The design of the PI controller depends on exact machine model. However, it is difficult for PMSM to obtain accurate $d-q$ axis reactance parameters, this makes it difficult for PI controller design. In addition, the single PI controllers are very susceptible to parameter variation, hence FLC is employed in speed and current regulators to replace the conventional PI controller. Figure 4 exhibits the overall block diagram of PMSM sensorless control system, with the proposed FLC and VSI nonlinearity compensation. The detailed chart of the FLC is illustrated in Figure 5, where $S_{r e f}, S_{f b}$ and $C_{r e f}$ stand for reference rotor speed, rotor speed feedback and reference current, respectively. It includes a PI controller and a fuzzy inference system. The design of FLC contains the following parts: 1) fuzzification, 2) MF of fuzzy inference system, 3) fuzzy rules, and 4) the input scaling factors $K_{e}$ and $K_{d e}$, and output scaling factors $K_{l}$ and $K_{2}$ (which are defined in Figure 5).

\subsection{Fuzzification}

Fuzzy set can be expressed as MF $\mu_{H}$ that associates with each element $x$ of the universe of discourse $X$, a number $\mu_{H}(x)$ in the interval $[0,1]$. The fuzzifier maps a

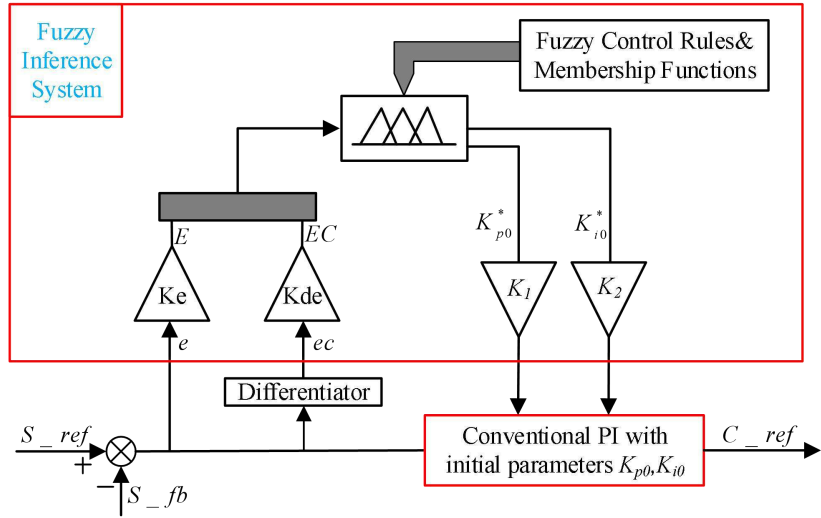

Figure 5 The diagram of a FLC for speed and current controllers.

clear input $x \in X$ to a fuzzified value $H \in U$ (Universe).

1) Singlet fuzzification: fuzzy set $H$ with support $x_{i}$, when $x=x_{i}, \mu_{H}\left(x_{i}\right)=1$, while $\mu_{H}\left(x_{i}\right)=0$, for $x \neq x_{i}$.

2) Non-singlet fuzzification: when $x=x_{i}, \mu_{H}\left(x_{i}\right)=1$, and it decreases from 1 to 0 when the distance away from $x=x_{i}$.

Besides the experimental trial-and-error method, the initial parameters of PI controller can also be estimated by simulations (see e.g. [31]). In practical application, the results can be directly employed to the control system design if the PI controller is utilized, however, they are only used a reference for setting up the initial values for the FLC.

\subsection{Design of MF}

The MF of Mandani FLC for input maps the normalized $E$ and $\mathrm{EC}$ to the membership degree from 0 to 1 . The scaling factors $K e$ and $K c$ are used for transforming the input into the fuzzy variables $E$ and $E C$, respectively. The transformation can be described as: 


$$
\left\{\begin{array}{l}
E=\mathrm{e} K_{e} \\
E C=e c K_{c}
\end{array}\right.
$$

where $e$ is error, $e c$ is error change rate.

A total of seven linguistic terms are considered for fuzzy partition to be used for the speed controller design, namely, 1) Positive Large (PL), 2) Positive Medium (PM), 3) Positive Small (PS), 4) Zero (ZE), 5) Negative Small (NS), 6) Negative Medium (NM), and 7) Negative Large (NL). Because $E$ and $E C$ are smaller than that of speed controller, 5 variables are considered in the current controller to reduce the calculation cost. Note that in the current controller, 5 linguistic variables are selected in the interval $[-2,2]$ as shown in Figure 6 . In terms of speed controller, the domains of $E$ and $E C$ are $[-6,6]$, while the domain of $U$ is $[0,6]$. Because $E$ and $E C$ are larger than that of the current error, 7 variables (rather than 5) are selected as shown in Figure 7. At both ends of the universe of discourse, the shape of fuzzy sets is trapezoidal, while the other intermediate fuzzy sets are triangular and overlap each other. The MF of the input characterized by FLC becomes insensitive when the input value is very small. As for the MF of the output, when $E$ and $E C$ remain small, the initial adjustment values $\left(k p_{0}{ }^{*}\right.$, $\left.k i_{0}{ }^{*}\right)$ barely change. Unlike the MF proposed in [39], the MF proposed in this paper focus on the dynamic and steady-state effectiveness of the control system.

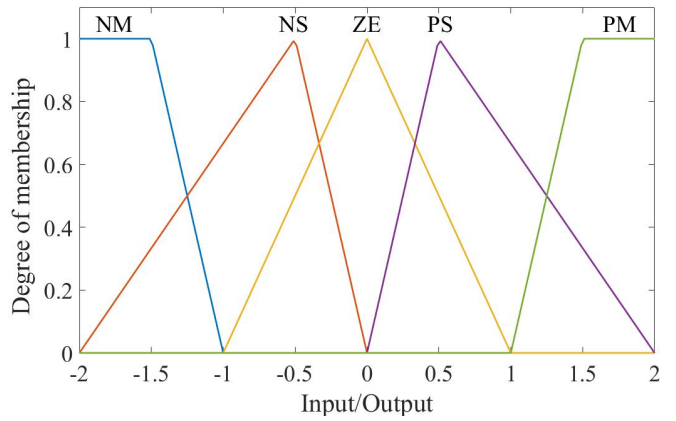

Figure 6 The MF for input and output of current controller.

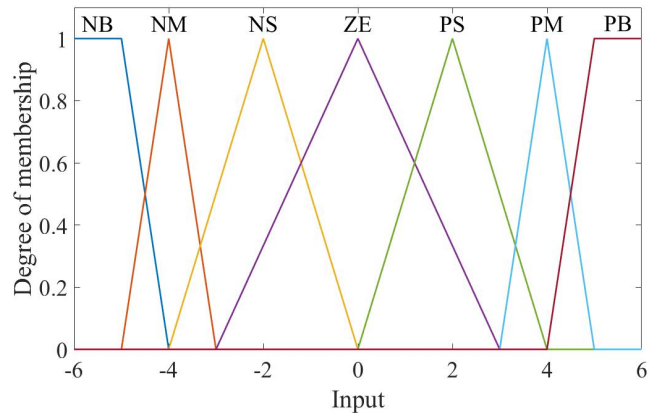

(a)

\subsection{Design of Fuzzy Rules}

In this paper, max-min composition reasoning method of Mamdani is employed. Depending on fundamental knowledge and expert experience, fuzzy rules, as the bond

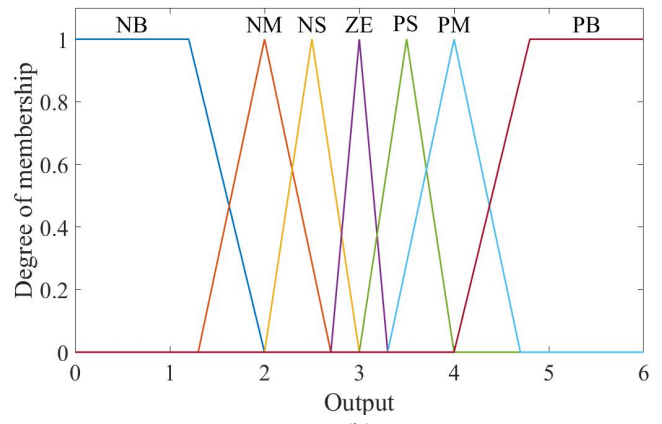

(b)

Figure 7 The MF for speed controller. (a) Input ( $E$ and $E C$ ). (b) Output $\left(\Delta K_{p}, \Delta K_{i}\right)$.

between input and output, play a crucial rule for achieving satisfactory control performance. Fuzzy control rule base is a set of IF-THEN rules, which can be expressed as follows:

$$
\begin{aligned}
& R^{l}: \text { IF } x_{1} \text { is } F_{1}^{l} \text { and } x_{2} \text { is } F_{2}^{l} \text { and ... and } x_{j} \text { is } F_{j}^{l} \\
& \text { THEN } y_{1} \text { is } G_{1}^{l} \text { and } y_{2} \text { is } G_{2}^{l} \text { and ... and } y_{k} \text { is } G_{k}^{l}
\end{aligned}
$$

where $x_{1} \in X_{1}, \ldots, x_{j} \in X_{j}$ are the input linguistic variables, and $y_{1} \in Y_{1}, \ldots, y_{k} \in Y_{k}$ are the output linguistic variables. $F_{n}^{l}$ is the input fuzzy labels, $G_{m}^{l}$ is the output fuzzy labels, the range of $n$ is $1, \ldots, j(j \in N)$, the range of $m$ is $1, \ldots, k(k \in N) . R^{l}$ is the fuzzy link between fuzzy input set $X$ to fuzzy output set $Y$.

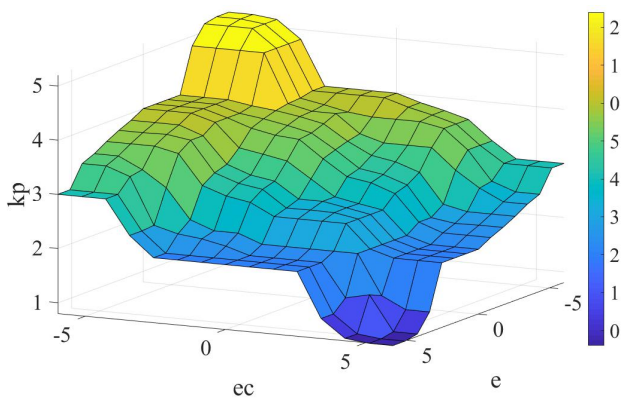

Figure 8 The output surface for $K p$ of speed controller.

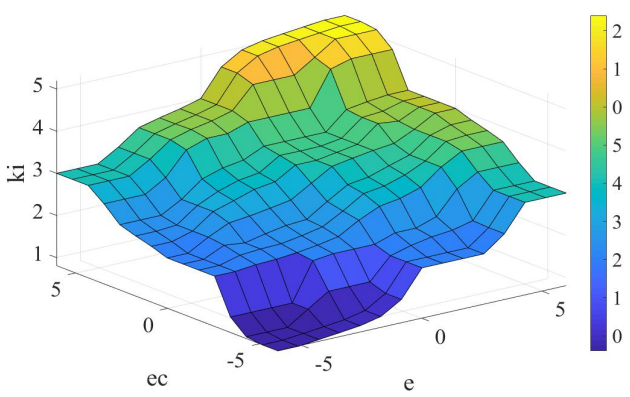

Figure 9 The output surface for $K i$ of speed controller.

The design of fuzzy rules for PMSM is depended on the following criteria: 
1) When $E$ is large, smaller $\Delta K i$ and larger $\Delta K p$ should be selected; When $E C$ is large, small $\Delta K i$ and moderate $\triangle K p$ should be chosen to decrease overshoot and accelerate the response of the system

2) When $E$ is medium, smalll $\Delta K i$ and moderate $\Delta K p$ should be removed; When $E C$ is medium, increase $\triangle K i$ and $\triangle K p$ to improve the steady-state effectiveness of the control system.

3) When $E$ and $E C$ are small, large $\Delta K i$ and $\Delta K p$ should be adopted to decrease error and improve the response speed of control system.

In the current controller, the MF with higher density near the origin can improve the steady-state accuracy [34]. The output surface of the fuzzy reasoning system is shown in Figure 8 and Figure 9. According to the above analysis, the control rules for the speed controller and current controller are exhibited in Table II and Table III, respectively.

Table 2 The fuzzy rules for $\mathrm{Kp} / \mathrm{Ki}$ of speed controller

\begin{tabular}{|c|c|c|c|c|c|c|c|}
\hline$E C$ & $N B$ & $N M$ & $N S$ & $Z E$ & $P S$ & $P M$ & $P B$ \\
\hline$N B$ & PB/NB & PB/NB & PM/NB & PM/NM & PS/NM & PS/ZE & ZE/ZE \\
\hline$N M$ & PB/NB & PB/NB & PM/NM & PM/NM & PS/NS & ZE/ZE & ZE/ZE \\
\hline$N S$ & PN/NM & PM/NM & PM/NM & PS/NM & ZE/ZE & NS/PS & NS/PS \\
\hline$Z E$ & PM/NM & PS/NS & PS/NS & ZE/ZE & NS/PS & NM/PS & NM/PM \\
\hline$P S$ & PS/NS & PS/NS & ZE/ZE & NS/PS & NS/PS & NM/PM & NM/PM \\
\hline$P M$ & ZE/ZE & ZE/ZE & NS/PS & NM/PM & NM/PM & NM/PB & NB/PB \\
\hline$P B$ & ZE/ZE & NS/ZE & NS/PS & NM/PM & NM/PB & NB/PB & NB/PB \\
\hline
\end{tabular}

Table 3 The fuzzy rules for $\mathrm{Kp} / \mathrm{Ki}$ of current controller

\begin{tabular}{|c|c|c|c|c|c|}
\hline$E$ & $N M$ & \multirow{2}{*}{$N S$} & $Z E$ & $P S$ & $P M$ \\
\hline$N M$ & $\mathrm{PM} / \mathrm{NM}$ & $\mathrm{PM} / \mathrm{NS}$ & $\mathrm{PS} / \mathrm{NS}$ & $\mathrm{PS} / \mathrm{ZE}$ & $Z \mathrm{ZE} / \mathrm{ZE}$ \\
\hline$N S$ & $\mathrm{PM} / \mathrm{NM}$ & $\mathrm{PM} / \mathrm{NS}$ & $\mathrm{PS} / \mathrm{NS}$ & $\mathrm{ZE} / \mathrm{ZE}$ & $\mathrm{ZE} / \mathrm{ZE}$ \\
\hline$Z E$ & $\mathrm{PS} / \mathrm{NS}$ & $\mathrm{ZE} / \mathrm{ZE}$ & $\mathrm{ZE} / \mathrm{ZE}$ & $\mathrm{NS} / \mathrm{PS}$ & NM/PS \\
\hline$P S$ & $\mathrm{ZE} / \mathrm{ZE}$ & $\mathrm{ZE} / \mathrm{ZE}$ & $\mathrm{NS} / \mathrm{PS}$ & $\mathrm{NS} / \mathrm{PS}$ & $\mathrm{NM} / \mathrm{PM}$ \\
\hline$P M$ & $\mathrm{ZE} / \mathrm{ZE}$ & $\mathrm{NS} / \mathrm{PS}$ & $\mathrm{NS} / \mathrm{PS}$ & $\mathrm{NS} / \mathrm{PM}$ & $\mathrm{NM} / \mathrm{PM}$ \\
\hline
\end{tabular}

\subsection{Design of Input/Output Scaling Factors}

$K e$ and $K d e$, as scaling factors, are utilized to map $E$ and $E C$ to the fuzzy region between -1 and 1 . They are similar to the gain coefficients of conventional PI controller and affect the stability, oscillations, and damping of the system. Therefore, $K a$ and $K d e$ need to be selected carefully.

Considering that flux weakening operation is not required [32], $K_{a}$ and $K_{d e}$ can be described as:

$$
\begin{gathered}
K_{a}=1 / e_{\max }=1 / n_{N} \\
K_{d e}=1 / e_{c \max }
\end{gathered}
$$

where $e_{\max }$ and $e_{c \max }$ are the maximum values of $E$ and $E C$ respectively, which can be extracted by simulation. $K_{l}$ and $K_{2}$ are employed to adjust the initial correction values $k p_{0} *$ and $k i_{0} *$ to the final adjustment values $k p^{*}$ and $k i^{*}$. Furthermore, the center of gravity defuzzification scheme is employed, which can be reported as:

$$
\text { Output }=\frac{\sum_{k=1}^{N} i \mu_{c(k)}(i)}{\sum_{k=1}^{N} \mu_{c(k)}(i)}
$$

where $N$ is the amount of fuzzy rules, and $\mu_{c(k)}(i)$ stand for the output membership grade for the rule with the output subset.

\section{Switch PI Control Based MRAS Observer for Sensorless Control}

\subsection{Switch PI Control for stator resistance tracking}

The core mission of the control system is to estimate the rotor speed after the command changes or the stator resistance varies with temperature. Therefore, the MRAS model is used to calculate the speed, position, and resistance of PMSM in this paper. An adaptive PI regulator is commonly used in MRAS, as shown in (15)-(17). It can be known that the estimation of rotor speed is affected by the PMSM parameters (i.e., stator resistance, inductance, and flux). These parameters change with load current and motor temperature. Therefore, if a single PI parameter is employed in MRAS, the observer can obtain higher accuracy only in a certain load range. This is why the system with a fixed MRAS observer based on an adaptive PI mechanism can only work steadily in a certain speed range.

In this paper, the switch PI system is employed for improving the estimation accuracy of rotor speed and stator resistance. Through different PI parameters, the sensitivity of the algorithm to the change of motor parameters is mitigated. In addition, when the motor starts, the integral component would reduce the stability of the control system and increase the overshoot; in steady state, the integral composition can improve the regulation ability of the system and eliminate the error [36]. The flowchart of switch PI scheme is shown in Figure 11. Let $Y$ be the current error variable, which can be written as:

$$
Y=\left[\left(i_{q}-\hat{i}_{q}\right) \hat{i}_{q}+\left(i_{d}-\hat{i}_{d}\right) \hat{i}_{d}\right]
$$

The implementation of the switch PI scheme includes the following three steps:

1) Based on the interval of $Y$, two threshold values $\mathrm{A}$ and $B$ are set.

2) The interval is split further according to the designed threshold. When $\frac{A}{2} \leq|Y| \leq B, k_{i}$ is set to 0 to prevent overshoot; otherwise, $k i$ is increased to speed up the resistance tracking.

3) The design of other integral separation controllers is the same as those in 2). 


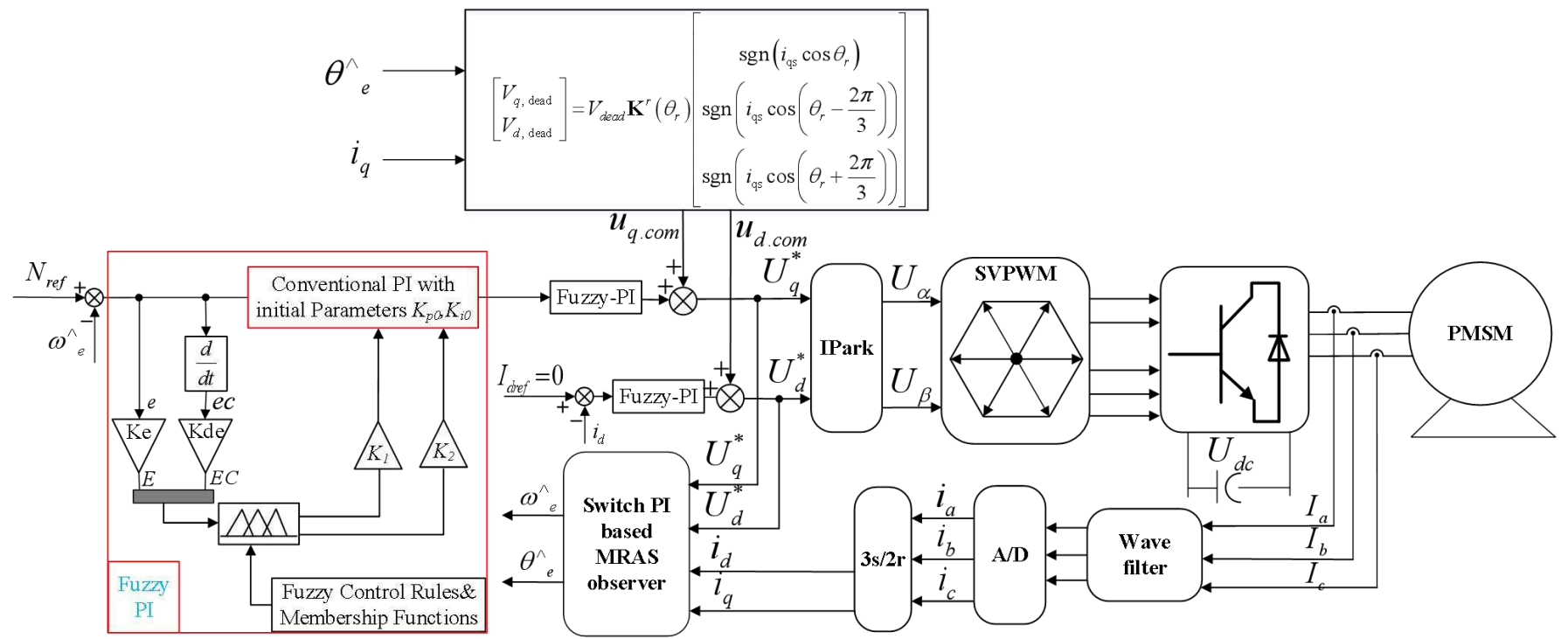

Figure 10 The diagram of the sensorless control system using the switch PI scheme based MRAS observer with FLC and VSI nonlinearity compensation strategy.

\subsection{Mathematical Model of the MRAS Observer}

In [35], Popov's hyperstability criterion was used to derive the adaptive algorithm, which has been verified in theory. Define

$$
\varepsilon(t)=i_{d} \hat{i}_{q}-i_{q} \hat{i}_{d}-\frac{\varphi_{f}}{L}\left(i_{q}-\hat{i_{q}}\right)
$$

Then the speed estimated by MRAS method can be written as:

$$
\hat{\omega}_{e}=\left(K_{p}+\frac{K_{i}}{S}\right) * \varepsilon(t)
$$

Combining (17) with (15), the resistance estimated by MRAS method can be written as:

$$
\hat{R}_{s}=-\left(K_{p i}+\beta \frac{K_{i i}}{p}\right) Y
$$

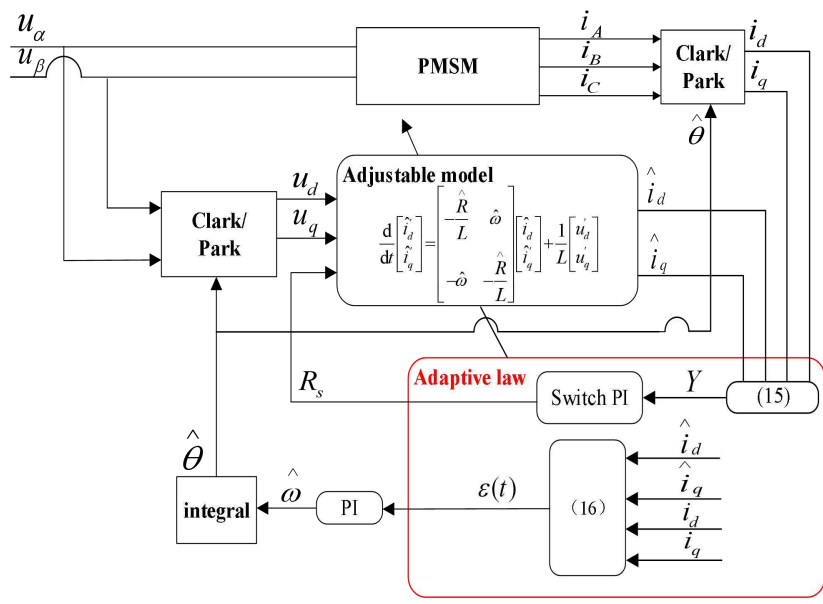

Figure 11 The improved MRAS observer based on switch PI scheme. where $\beta$ is the switching coefficient of the integral term. When $|\mathrm{Y}| \leq \mathrm{A} / 2, \beta=1$; otherwise $\beta=0$. The identification equation of the electric angle is the integration of the identification equation of estimated speed:

$$
\hat{\theta}=\int \hat{\omega}_{e}
$$

Based on (14)-(18) and Figure 11, the block diagram of the MRAS observer based on switch PI scheme is shown in Figure 12. The whole block diagram of the MRAS observer for estimating speed, position and resistance, fuzzy logic controller for speed and current loop, and the DTCV strategy, is exhibited in the Figure 10.

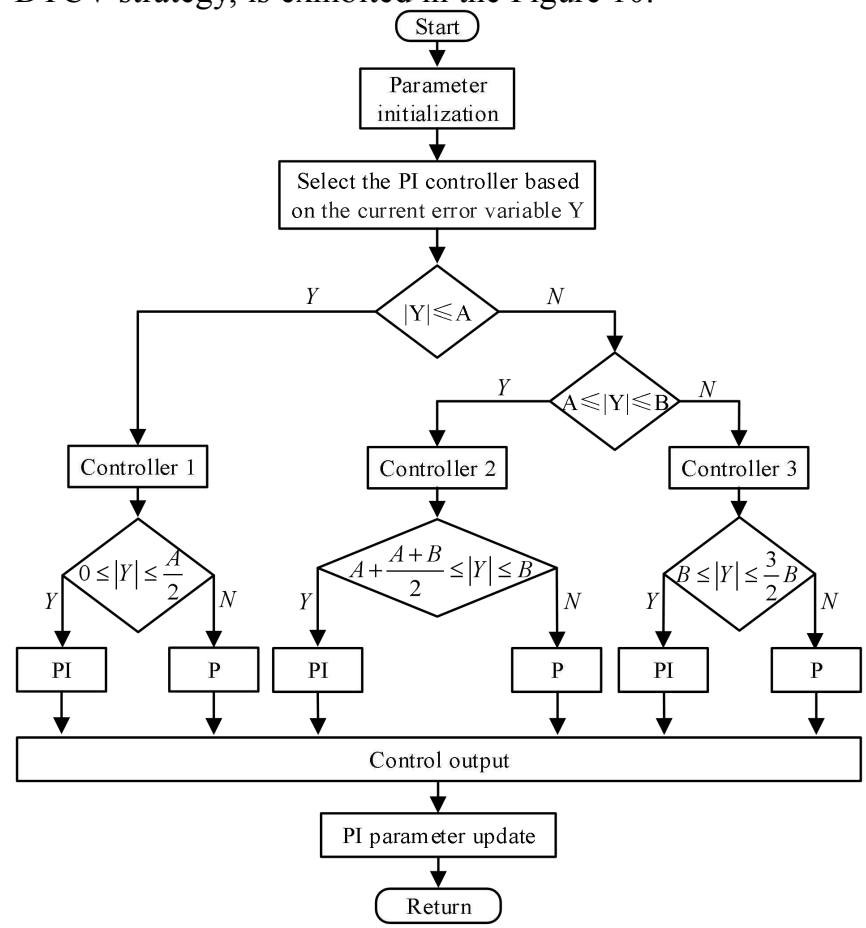

Figure 12. The flowchart of switch PI control based on MARS observer for resistance tracking. 


\section{Experimental Waveforms and Analysis}

\subsection{Configuration of the Platform}

The TMS320F28035 DSP is employed for parameter estimation of the prototype machine. The relevant parameters are exhibited in Table IV and the platform setup is given in Figure 13. The Simulation results are exhibited to prove the robustness of the switch PI scheme based on MRAS observer for the sensorless control and stator resistance tracking of PMSM drives. The gains used for the tuning of the adaptive mechanism of resistance are shown in Table V. In all the tests, the double-closed-loop system of speed and current is employed. To testify the robustness of the system, the measured speed error during steady stage is studied by considering disturbance such as step change of speed command or stator resistance variation.

\subsection{Experimental Results and Analysis}

In order to show the superiority of the introduced switch PI scheme based on MRAS observer, the following four schemes are introduced and investigated.

1) The Step Change of Stator Resistance: In practice, the resistance of PMSM usually varies with the temperature. To reflect this fact and verify the robustness of control performance, in the experiments the big change

Table 4 Reference parameters of the PMSM

\begin{tabular}{cc}
\hline \hline Parameters & Values \\
\hline \hline Nominal speed & $3000 \mathrm{rpm}$ \\
Nominal current $I_{N}$ & $6.8 \mathrm{~A}$ \\
Nominal voltage $U_{N}$ & $380 \mathrm{~V}$ \\
Nominal power & $4.0 \mathrm{KW}$ \\
DC bus voltage & $311 \mathrm{~V}$ \\
$d / q$-axis inductance $L_{d} / L_{q}$ & $15.86 \mathrm{mH}$ \\
Permanent magnet flux $\varphi_{f}$ & $79 \mathrm{mWb}$ \\
Number of pole pairs $p$ & 4 \\
Stator resistance $\Omega$ & $1.204 \Omega$ \\
\hline \hline
\end{tabular}

Table 5 Parameters employed in switch PI scheme for resistance tracking

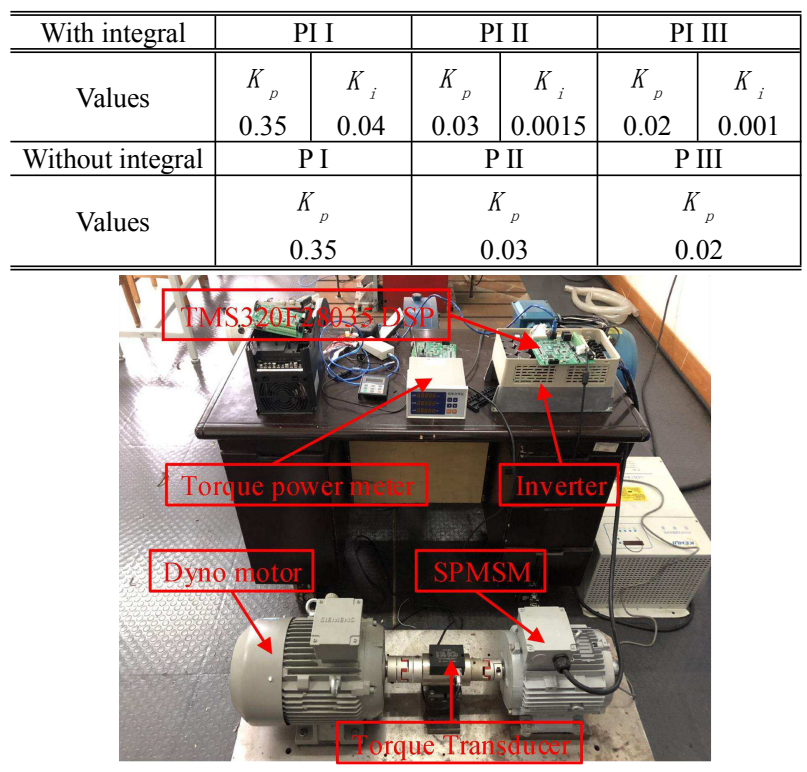

Figure 13 The used prototype PMSM. of stator resistance is considered accordingly, and the reference speed is set as $1000 \mathrm{rpm}$. The experimental results based on two sets of resistance changes are shown in Figure 14 and Figure 15, where 'Ref' represents the reference value of stator resistance. In Figure 14(a), the change process of resistance is as follows: $1.204 \Omega$ (initial value) $\rightarrow 1.806 \Omega$ (1.5 times of the initial value) $\rightarrow$ $1.204 \Omega \rightarrow 0.903 \Omega(75 \%$ of the initial value $) \rightarrow 1.204 \Omega$. It shows that the switch PI scheme has a higher accuracy for estimating the resistance than the conventional PI scheme. Figure 14(b) shows the relevant estimated speed when the resistance changes. It shows that the steady-state and dynamic performance based on this method are better. When the resistance varies from $1.204 \Omega$ to $1.806 \Omega$, the speed oscillates at the time of $1 \mathrm{~s}$ and only takes 0.1 seconds to recover. Similarly, the speed changes at the time of $2 \mathrm{~s}, 3 \mathrm{~s}$, and $4 \mathrm{~s}$ due to the changes of the resistance. In Figure 15(a), the change process of resistance is as below: $1.204 \Omega$ (initial value) $\rightarrow 2.528 \Omega$ (2.1 times of the initial value) $\rightarrow 1.806 \Omega$ (1.5 times of the initial value) $\rightarrow$ $1.0836 \Omega(0.9$ times of the initial value $) \rightarrow 0.8428 \Omega(0.7$ times of the initial value). It shows that the steady-state error is less than $7.2 \%$. The relevant estimated speed when the resistance changes is exhibited in Figure 15(b). Therefore, the performance of the sensorless control for PMSM is effective in the proposed MRAS model based on the switch PI scheme via resistance tracking.

2) The Step Change of Reference Speed: In this experiment, the speed was set to be square wave signal but the stator resistance remains to be $1.204 \Omega$. The step response (from $1000 \mathrm{rpm}$ to $500 \mathrm{rpm}$ ) and the estimated values of the rotor speed are exhibited in Figure 16(a). It shows that the estimated rotor speed based on the scheme of FLC can quickly track the command with a smaller steady-state error compared to the traditional PI controller. It also shows that there is no overshoot in the speed transition. The estimated rotor speed error is $\pm 0.1 \mathrm{rad} / \mathrm{s}$. The error can be large only when the speed suddenly changes such as at $1 \mathrm{~s}, 2 \mathrm{~s}, 3 \mathrm{~s}$, and $4 \mathrm{~s}$. Figure 16(b) shows that the zoomed estimation error of rotor position is at around $\pm 1^{\circ}$.

3) The Effect of Stator Resistance Estimation: The performance with the online estimation scheme for resistance is compared with that of without estimation scheme. The relevant results are exhibited in Figure 17. Obviously, the dynamic performance and estimation accuracy of sensorless control are greatly improved if the stator resistance is online estimated.

4) The Effect of DTCV Strategy: The sensorless control performances, with/without DTCV, are given in Figure 18. It can be seen that the system with DTCV not only has higher efficiency but also will not appear overshoot and undershoot. The error of the estimated speed without DTCV is also larger than that with DTCV. The estimation of stator resistance is exhibited in Figure 18(b). It shows that the stator resistance tracks more closely when DTCV is considered. The experimental results of $D_{d}$ and $D_{q}$ 


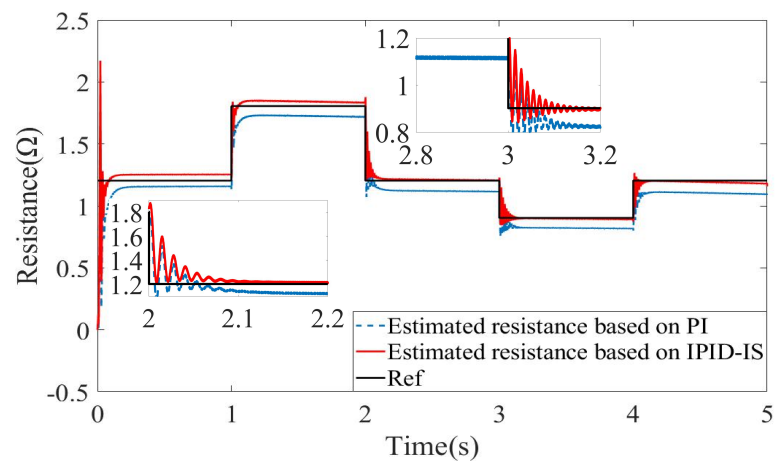

(a)

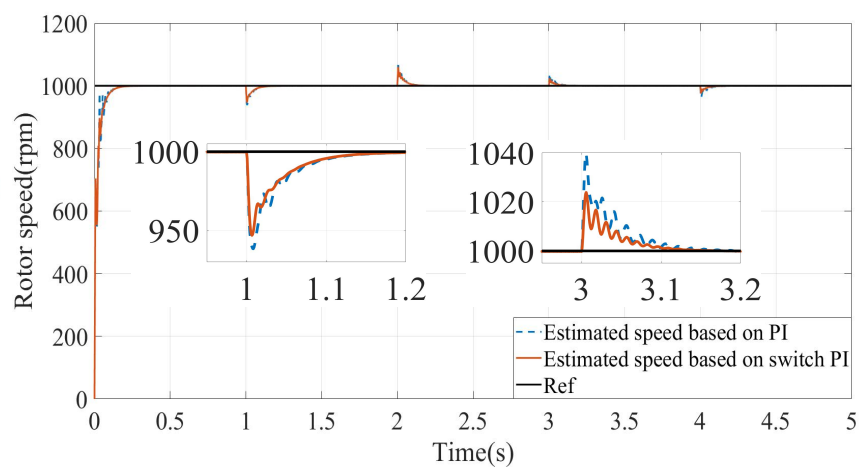

(b)

Figure 14 The comparison results for resistance variation $(1.204 \Omega \rightarrow 1.806 \Omega \rightarrow 1.204 \Omega \rightarrow 0.903 \Omega \rightarrow 1.204 \Omega$ ). (a) Resistance tracking. at $1000 \mathrm{rpm}$. (b) Rotor speed tracking under resistance variation.

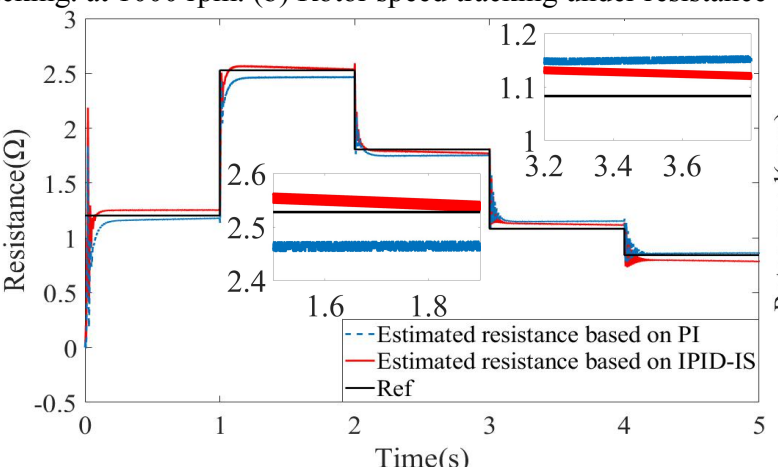

(a)

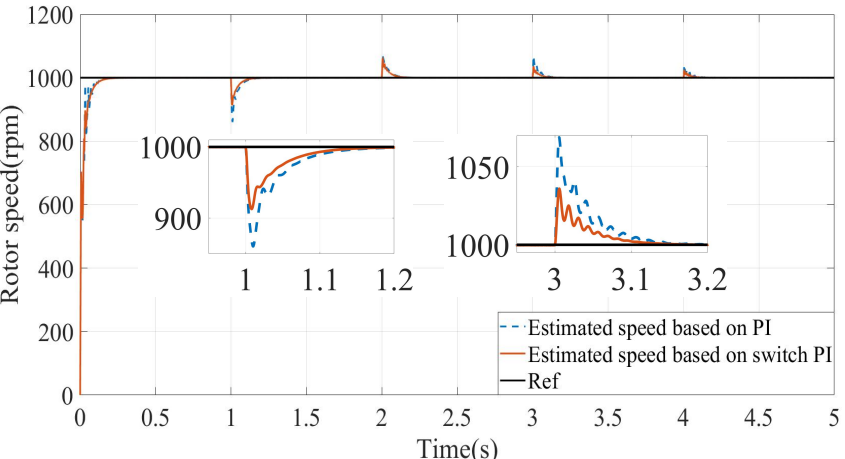

(b)

Figure 15 The comparison results for resistance variation $(1.204 \Omega \rightarrow 2.528 \Omega \rightarrow 1.806 \Omega \rightarrow 1.0836 \Omega \rightarrow 0.8428 \Omega$ ). (a) Resistance tracking at $1000 \mathrm{rpm}$. (b) Rotor speed tracking under resistance variation.

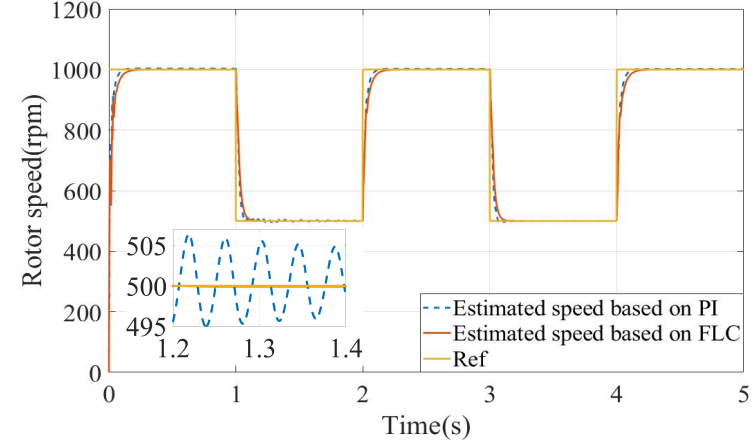

(a)

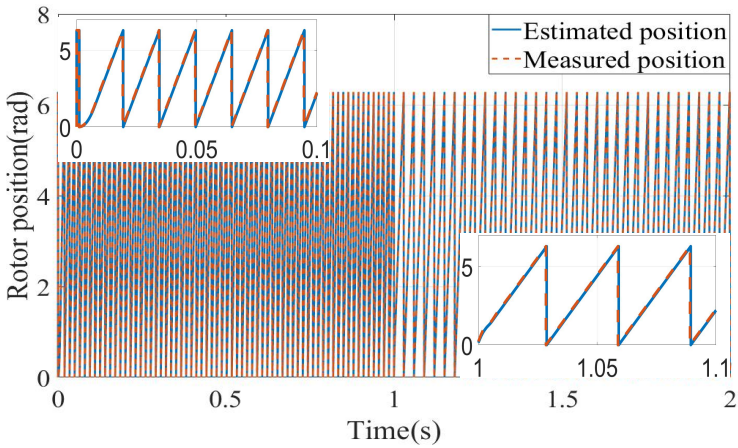

(b)

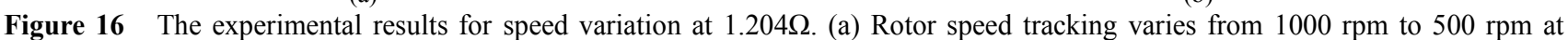
$1.204 \Omega$. (b) Zoomed rotor position estimation.

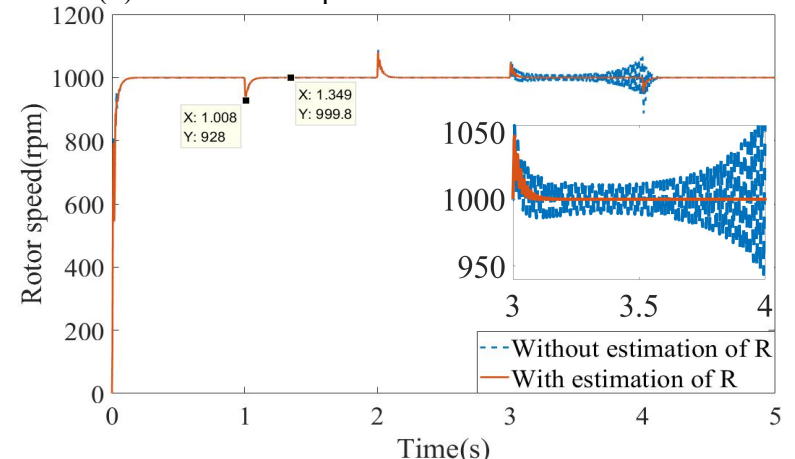

(a)

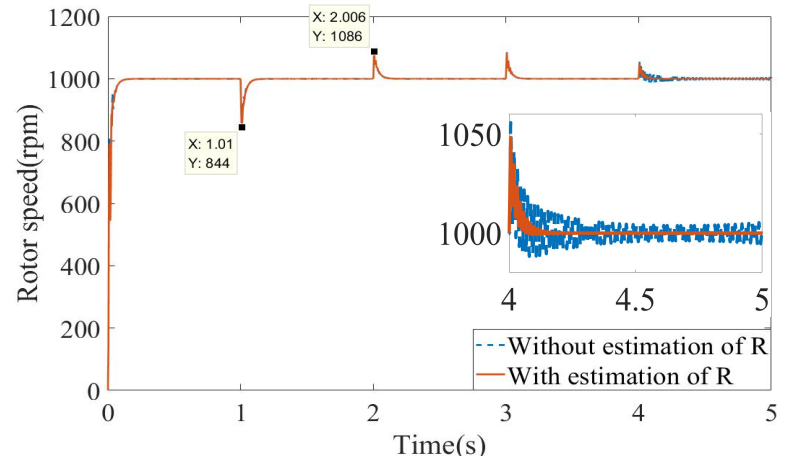

(b)

Figure 17 The resistance and speed tracking under resistance variation. (a) Comparison between online/no estimation of resistance $(1.204 \Omega \rightarrow 1.806 \Omega \rightarrow 1.204 \Omega \rightarrow 0.903 \Omega \rightarrow 1.204 \Omega)$. (b) Comparison between online/no estimation of resistance $(1.204 \Omega \rightarrow 2.528 \Omega$ $\rightarrow 1.806 \Omega \rightarrow 1.0836 \Omega \rightarrow 0.8428 \Omega$ ). 


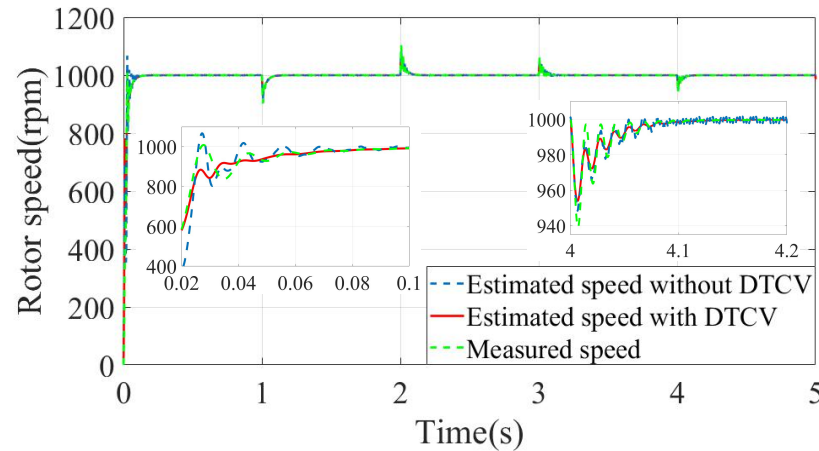

(a)

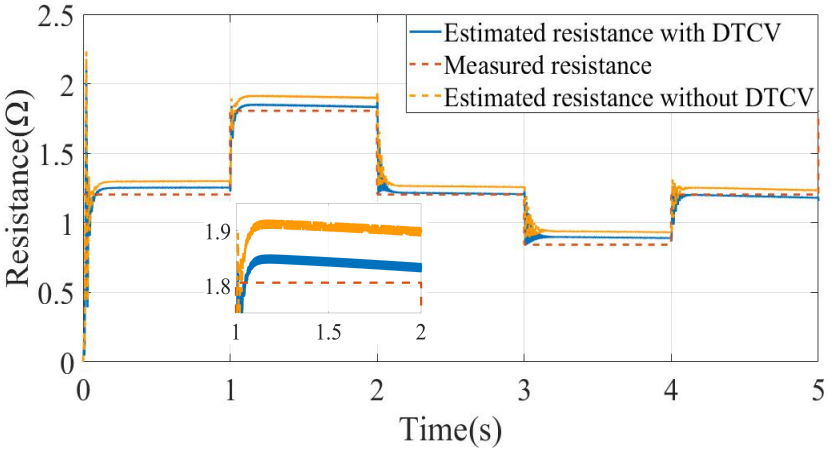

(b)

Figure 18 The resistance and speed tracking under resistance variation $(1.204 \Omega \rightarrow 1.806 \Omega \rightarrow 1.204 \Omega \rightarrow 0.903 \Omega \rightarrow 1.204 \Omega)$. (a) Comparison of speed estimation with and without DTCV strategy. (b) Comparison of stator resistance estimation with and without DTCV strategy.

Table 6 The comparison between PI controller and fuzzy logic controller for sensorless control

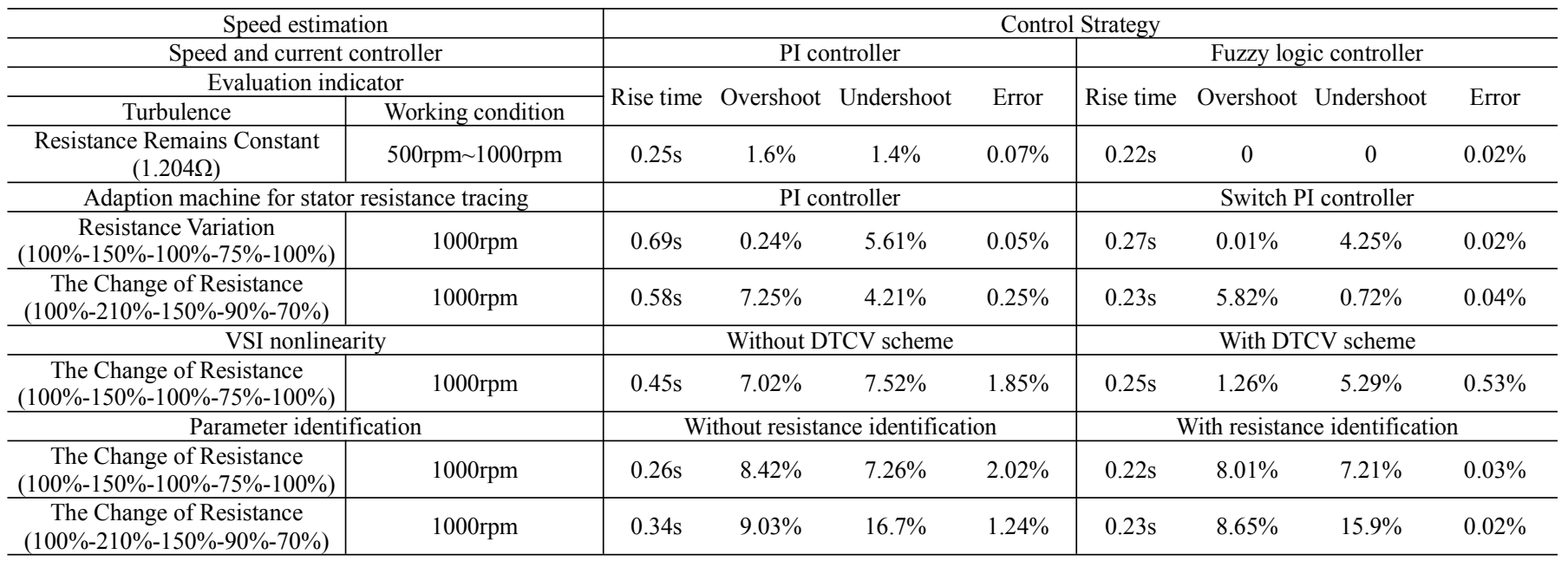

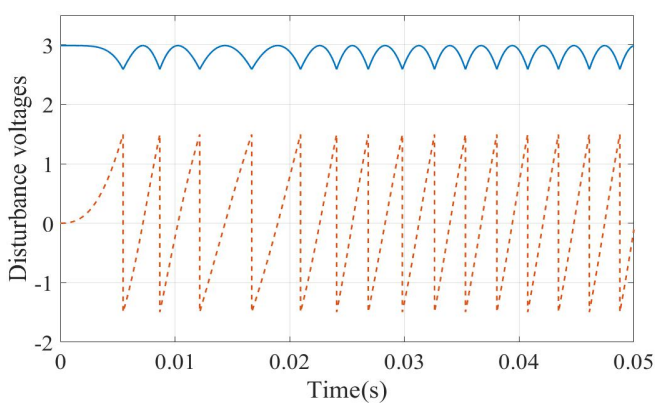

Figure 19 The results of $D_{d} / D_{q}$ under the $i_{d}=0$ scheme and the reference rotor speed is $1000 \mathrm{rpm}$ (Continuous line: $q$-axis turbulence voltage $V_{q, d e a d}$. Discontinuous line: $d$-axis turbulence voltage $\left.V_{\text {d,dead }}\right)$.

are given in Figure 19, under the $i_{d}=0$ control method and the reference speed is $1000 \mathrm{rpm}$. It shows that the $V_{q}^{\text {com }}$ is an alternating voltage and the $V_{d}^{\text {com }}$ is the voltage with constant direction. A detailed comparison exhibiting the superiority of the introduced scheme is shown in Table VI.

\section{Conclusions}

In this manuscript, a switched PI system based on MRAS observer using a FLC is introduced for sensorless control of PMSM field, which can help decrease the overshoot of stator resistance tracking and enhance the effectiveness of sensorless control. The experimental under the variable speed and variable resistance is investigated. The sensorless control and resistance estimation considering DTCV strategy are also investigated under the working condition of speed variation. The following conclusions can be drawn from the experimental results:

(1) The introduced FLC can quickly track the reference speed with a smaller steady-state error compared to traditional PI controller. In addition, the switch PI scheme based on MRAS observer can obtain better dynamic performance. The motor has a strong robustness to parameter variation.

(2) When the stator resistance changes from 2.1 times to 
0.7 times, the MRAS observer can track closely and the error is less than $4.8 \%$; there is no overshoot in the estimated resistance when the resistance changes suddenly. Furthermore, the control performance can be improved if the stator resistance is identified online.

(3) The dynamic performance and tracking precision of the sensorless control and stator resistance identification could be improved when the DTCV scheme is employed.

In conclusion, using the proposed scheme, the performance of PMSM sensorless control is robust and effective. In future, experiments will be performed on an actual platform to further test the performance of the proposed control schme.

\section{Declaration}

\section{Acknowledgements \\ Not applicable.}

\section{Availability of data and materials}

No datasets presented.

\section{Authors' contributions}

$\mathrm{Z}-\mathrm{H} \mathrm{L}$ was in charge of the whole research; JN wrote the manuscript; H-L $\mathrm{W}$ discussed and read the manuscript; F-M W and LC assisted with the analysis and validation; $\mathrm{ZZ}$ provided the motor test platform. All authors read and approved the fnal manuscript.

\section{Authors' Information}

Zhao-Hua Liu (M'16) born in 1983, received M.Sc. degree in computer science and engineering, and the $\mathrm{PhD}$. degree in automatic control and electrical engineering from the Hunan University, China, in 2010 and 2012, respectively. He worked as a visiting researcher in the Department of Automatic Control and Systems Engineering at the University of Sheffield, United Kingdom, from 2015 to 2016. He is currently an Associate Professor with the School of Information and Electrical Engineering, Hunan University of Science and Technology, Xiangtan, China. His current research interests include computational intelligence and learning algorithms design, parameter estimation and control of permanent-magnet synchronous machine drives, and condition monitoring and fault diagnosis for power system. Dr. Liu has published a monograph in the field of Biological immune system inspired hybrid intelligent algorithm and its applications, and published more than 30 research papers in refereed journals and conferences, including IEEE TRANSACTIONS/JOURNAL/MAGAZINE. He is a regular reviewer for several international journals and conferences.

Jie Nie born in 1997, received B. Eng. degree in Electrical engineering and automation from the Hunan university of science and technology, Xiang tan, China, in 2019. He is currently pursuing the M.S. degree in the electrical engineering, at Hunan University of Science and Technology, Xiangtan, China. His current research interests include parameter identification, and sensorless control for permanent magnet synchronous motor.

Hua-Liang Wei, received the Ph.D. degrees in automatic control from The University of Sheffield, Sheffield, U.K., in 2004.

$\mathrm{He}$ is currently a senior lecturer with the Department of Automatic Control and Systems Engineering, The University of Sheffield, Sheffield, UK. His research focuses on evolutionary algorithms, identification and modelling for complex nonlinear systems, applications and developments of signal processing, system identification and data modelling to control engineering.

Fa-Ming Wu born in 1983, received M.S. degree in Lanzhou University of Technology, China, in 2021. He is a senior engineer of CRRC Zhuzhou Institute Company Ltd. His current research interests include mechanical dynamics analysis and fault diagnosis

Lei Chen born in 1986, received M.S. degree in computer science and engineering, and the $\mathrm{PhD}$. degree in automatic control and electrical engineering from the Hunan University, China, in 2012 and 2017, respectively. He is currently a Lecturer with the School of Information and Electrical Engineering, Hunan University of Science and Technology, Xiangtan, China. His current research interests include deep learning, network representation learning, information security of industrial control system and big data analysis.

\section{Zhu Zhang,}

Zhang Zhu received his B. S. degree in 2004 from Hunan Institute Of Engineering, received his M.Sc. degree in 2007 form South China University of Technology, received his Ph.D. degree in 2012 form The Hong Kong Polytechnic University, now he is lecturer in Hunan University of Science and Technology. His main research interests include power electronics and electrical driver system, Intelligent control.

\section{Funding}

Supported in part by the National Natural Science Foundation of China under Grant 61972443, National Key Research and Development Project under Grant 2019YFE0105300, in part by the Hunan Provincial Hu-Xiang Young Talents Project of China under Grant 2018RS3095, in part by the Hunan Provincial Natural Science Foundation of China under Grant 2018JJ2134 and Grant 2020JJ5199, and in part by the Scientific Research Fund of Hunan Provincial Education Department under Grant $18 \mathrm{C} 0296$ and 19B200.

\section{Competing interests}

The authors declare no competing financial interests.

\section{Author Details}


${ }^{1}$ the School of Information and Electrical Engineering, Hunan University of Science and Technology, Xiangtan 411201, China. ${ }^{2}$ the Department of Automatic Control and Systems Engineering, University of Sheffield, Sheffield S1 3JD, U.K. ${ }^{3}$ CRRC Zhuzhou Institute Company Ltd, Zhuzhou, 412007, China.

\section{References}

[1] S. Li, B. Sarlioglu, S. Jurkovic, N. R. Patel and P. Savagian, "Comparative analysis of torque compensation control algorithms of interior permanent magnet machines for automotive applications considering the effects of temperature variation," IEEE Trans. Transport. Electrific., vol. 3, no. 3, pp. 668-681, Sept. 2017.

[2] He, W., Wu, X., Chen, J. and Wang, Y., "Comparative study of sensorless control of Permanent magnet synchronous motor realised by sliding-mode observer," IET Power Electron., vol. 13, no. 6, pp. 1191-1199, Feb. 2020.

[3] C. Lu, S. Ferrari and G. Pellegrino, "Two design procedures for PM synchronous machines for electric powertrains," IEEE Trans. Transport. Electrific., vol. 3, no. 1, pp. 98-107, March 2017.

[4] S. Murshid and B. Singh, "Implementation of PMSM Drive for a Solar Water Pumping System," IEEE Trans on Ind. Appl., vol. 55, no. 5, pp. 4956-4964, Sept.-Oct. 2019.

[5] A. V. R. Teja, V. Verma, and C. Chakraborty, "A New Formulation of Reactive-Power-Based Model Reference Adaptive System for Sensorless Induction Motor Drive," IEEE Trans. Ind. Electron, vol. 62, no. 11, pp. 6797-6808, Nov. 2015.

[6] C. M. Verrelli et al., "Speed Sensor Fault Tolerant PMSM Machines: From Position-Sensorless to Sensorless Control," IEEE Trans. Ind. Appl, vol. 55, no. 4, pp. 3946-3954, Jul.-Aug. 2019.

[7] T. Boileau, N. Leboeuf, B. Nahid-Mobarakeh, and F. Meibody-Tabar, "Online Identification of PMSM Parameters: Parameter Identifiability and Estimator Comparative Study," IEEE Trans. Ind. Appl, vol. 47, no. 4, pp. 1944-1957, Jul.-Aug. 2011.

[8] H. Tajima and Y. Hori, "Speed sensorless field-orientation of the induction machine," IEEE Trans. Ind. Appl., vol. 29, no. 1, pp. 175-180, Jan./Feb. 1993.

[9] J.-K. Seok, J.-K. Lee, and D.-C. Lee, "Sensorless speed control of nonsalient permanent-magnet synchronous motor using rotor-positiontracking PI controller," IEEE Trans. Ind. Electron., vol. 53, no. 2, pp. 399- 405, Apr. 2006.

[10] T.-S. Low, T.-H. Lee, and K.-T. Chang, "A nonlinear speed observer for permanent-magnet synchronous motors," IEEE Trans. Ind. Electron., vol. 40, no. 3, pp. 307-316, Jun. 1993.

[11] F. Aghili, "Energy-efficient and fault-tolerant control of multiphase non-sinusoidal pm synchronous machines," IEEE/ASME Trans. Mechatron., vol. 20, no. 6, pp. 2736-2751, Dec. 2015.

[12] B. Stumberger, G. Stumberger, D. Dolinar, A. Hamler, and M. Trlep, "Evaluation of saturation and cross-magnetization effects in interior permanent-magnet synchronous motor," IEEE Trans. Ind. Appl., vol. 39, no. 5, pp. 1264-1271, Sep. 2003.

[13] Z. Yin, R. Tang, C. Du, and Y. Wang, "Moment of Inertia Identification Based on Unscented Kalman Filter for Permanent Magnet Synchronous Motors," in Proc. 2019 14th IEEE Conference on Industrial Electronics and Applications (ICIEA), Xi'an, China, pp. 1141-1145, 2019.

[14] Y. Shi, K. Sun, L. Huang, and Y. Li, "Online identification of permanent magnet flux based on extended Kalman filter for IPMSM drive with position sensorless control," IEEE Trans. Ind. Electron., vol. 59, no. 11, pp. 4169-4178, Nov. 2012.

[15] A. Balamurali, C. Lai, G. Feng, V. Loukanov, and N. C. Kar, "Online multi-parameter identification of permanent magnet synchronous motors in EV application considering iron losses," in Proc. 2016 XXII International Conference on Electrical Machines (ICEM), Lausanne, pp. 2306-2312, 2016.

[16] S. J. Underwood and I. Husain, "Online parameter estimation and adaptive control of permanent-magnet synchronous machines," IEEE Trans. Ind. Electron., vol. 57, no. 7, pp. 2435-2443, Jul. 2010.
[17] K. Liu, Z.-Q. Zhu, and D. A. Stone, "Parameter estimation for condition monitoring of PMSM stator winding and rotor permanent magnets," IEEE Trans. Ind. Electron., vol. 60, no. 12, pp. 5902-5913, Dec. 2013.

[18] E. Zerdali and M. Barut, "MRAS based real-time speed-sensorless control of induction motor with optimized fuzzy-PI controller," in Proc. 2013 IEEE International Symposium on Sensorless Control for Electrical Drives and Predictive Control of Electrical Drives and Power Electronics (SLED/PRECEDE), Munich, pp. 1-5, 2013.

[19] Y. Mei, K. Sun, and Y. Shi, "A 2-D fuzzy logic based MRAS scheme for sensorless control of interior permanent magnet synchronous motor drives with cyclic fluctuating loads," Chinese Journal of Electrical Engineering, vol. 1, no. 1, pp. 85-91, Dec. 2015.

[20] S. E. Rezgui, S. Legrioui, A. Mehdi, and H. Benalla, "Robust IM control with MRAS-based speed and parameters estimation with ANN using exponential reaching law," in Proc. 2014 International Conference on Control, Decision and Information Technologies (CoDIT), Metz, pp. 477-482, 2014.

[21] Y. A. I. Mohamed, “A Newly Designed Instantaneous-Torque Control of Direct-Drive PMSM Servo Actuator With Improved Torque Estimation and Control Characteristics," IEEE Trans. Ind. Electron, vol. 54, no. 5, pp. 2864-2873, Oct. 2007.

[22] K.-Y. Cheng and Y.-Y. Tzou, "Fuzzy optimization techniques applied to the design of a digital PMSM servo drive," IEEE Trans. Power Electron., vol. 19, no. 4, pp. 1085-1099, Jul. 2004.

[23] K. M. A. Prasad, U. Nair, and A. Unnikrishnan, "Fuzzy sliding mode control of a Permanent Magnet Synchronous Motor with two different fuzzy membership functions," in Proc. 2015 International Conference on Power, Instrumentation, Control and Computing (PICC), Thrissur, pp. 1-6, 2015.

[24] G. V. Lakhekar, L. M. Waghmare, and R. G. Roy, "Disturbance Observer-Based Fuzzy Adapted S-Surface Controller for Spatial Trajectory Tracking of Autonomous Underwater Vehicle," IEEE Trans. Intell. Veh., vol. 4, no. 4, pp. 622-636, Dec. 2019.

[25] C. Zhou et al., "An Improved Direct Adaptive Fuzzy Controller of an Uncertain PMSM for Web-Based E-Service Systems," IEEE Trans. Fuzzy Syst., vol. 23, no. 1, pp. 58-71, Feb. 2015.

[26] M. N. Uddin, Z. R. Huang, and A. B. M. S. Hossain, "Development and Implementation of a Simplified Self-Tuned Neuro-Fuzzy-Based IM Drive," IEEE Trans. Ind. Appl., vol. 50, no. 1, pp. 51-59, Jan.-Feb. 2014.

[27] F. Lin, I. Sun, K. Yang, and J. Chang, "Recurrent Fuzzy Neural Cerebellar Model Articulation Network Fault-Tolerant Control of Six-Phase Permanent Magnet Synchronous Motor Position Servo Drive," IEEE Trans. Fuzzy Syst., vol. 24, no. 1, pp. 153-167, Feb. 2016.

[28] Z. Liu, H. Wei, Q. Zhong, K. Liu and X. Li, "GPU Implementation of DPSO-RE Algorithm for Parameters Identification of Surface PMSM Considering VSI Nonlinearity," IEEE J. Emerg. Sel. Topics Power Electron., vol. 5, no. 3, pp. 1334-1345, Sept. 2017.

[29] H.-S. Kim, H.-T. Moon, and M.-J. Youn, "On-line dead-time compensation method using disturbance observer," IEEE Trans. Power Electron., vol. 18, no. 6, pp. 1336-1345, Nov. 2003.

[30] G. Feng, C. Lai, K. Mukherjee, and N. C. Kar, "Current Injection-Based Online Parameter and VSI Nonlinearity Estimation for PMSM Drives Using Current and Voltage DC Components," IEEE Trans. Transport. Electrific., vol. 2, no. 2, pp. 119-128, Jun. 2016.

[31] A. Mishra, G. Dubey, D. Joshi, P. Agarwal, and S. P. Sriavstava, “A Complete Fuzzy Logic Based Real-Time Simulation of Vector Controlled PMSM Drive," in Proc. 2018 2nd IEEE International Conference on Power Electronics, Intelligent Control and Energy Systems (ICPEICES), Delhi, India, pp. 809-814, 2018.

[32] J. L. Liu, C. Gong, Z. X. Han, and E. Y. Zhang, "An improved adaptive fuzzy PID controller for PMSM and a novel stability analysis method," in Proc. 2017 IEEE 3rd International Future Energy Electronics Conference and ECCE Asia (IFEEC 2017 ECCE Asia), Kaohsiung, pp. 2161-2164, 2017.

[33] P. H. Krishnan and M. Arjun, "Control of BLDC motor based on adaptive fuzzy logic PID controller," in Proc. 2014 International 
Conference on Green Computing Communication and Electrical Engineering (ICGCCEE), Coimbatore, pp. 1-5, 2014.

[34] S. P. Singh, A. K. Gautam, J. Dubey, J. P. Pandey, and R. P. Payasi, "Performance comparison of PMSM drive using PI and Fuzzy Logic based controllers," in Proc. 2016 IEEE Uttar Pradesh Section International Conference on Electrical, Computer and Electronics Engineering (UPCON), Varanasi, pp. 563-569, 2016.

[35] M. Tomita, T. Senjyu, S. Doki, and S. Okuma, "New sensorless control for brushless DC motors using disturbance observers and adaptive velocity estimations," IEEE Trans. Ind. Electron., vol. 45, no. 2, pp. 274-282, Apr. 1998.

[36]R. Na and X. Wang, "An Improved Vector-Control System of PMSM Based on Fuzzy Logic Controller," in Proc. 2014 International Symposium on Computer, Consumer and Control, Taichung, pp. 326-331, 2014. 